\title{
THERMO-ELASTIC ANALYSIS OF FGM PLATES BASED ON HIGHER ORDER REFINED COMPUTATIONAL MODEL
}

\author{
K. Swaminathan ${ }^{1}$, D. M. Sangeetha ${ }^{2}$ \\ ${ }^{1,2}$ Department of Civil Engineering, National Institute of Technology Karnataka, Surathkal, Mangalore 575025, \\ India. ${ }^{1}$ swami7192@yahoo.co.in, ${ }^{2}$ ursang2008@gmail.com
}

\begin{abstract}
In this paper, analytical formulations and solutions hitherto not reported in the literature are presented for the thermally loaded simply supported Functionally Graded Material (FGM) plates. Higher order refined computational model with twelve degrees-offreedom based on Taylor's series of expansion of displacements, which includes the effect of transverse shear and transverse normal stress / strain is considered for the study. The equations of equilibrium are obtained using Principle of Minimum Potential Energy (PMPE) and closed form solutions using Navier's Solution technique. The material properties are assumed to vary according to power law function. The temperature across the plate thickness is assumed to be nonlinear and is solved based on one dimensional steady state heat conduction equation. The accuracy of the presented two-dimensional model is first established by comparing the results with the exact 3-D elasticity solutions already reported in the literature. Upon establishing the accuracy, numerical results are obtained for the FGM plates subjected to thermal loads with varying material and plate parameters. Studies are performed by varying the length to breadth ratio, side-to-thickness ratio and power law parameter. Bench mark results using the present model are presented for the displacements, in-plane and transverse stresses.
\end{abstract}

Keywords: Functionally graded plate, Thermal stress analysis, Shear deformation, Analytical solutions, Higher order refined theory.

\section{INTRODUCTION}

Functionally Graded Materials (FGMs) are the innovative materials emerged from composites, in which two distinct materials preferably ceramic and metal are graded continuously from one to another. FGMs carry the advantages of both ceramic and metal, like high toughness, strength, durability, thermal and fracture resistance etc. Major applications are found in high temperature zones like nuclear components, satellite thermal shields, thermal barrier coatings, etc., thereby provoking the interest of researchers in thermal analysis of FGM plates.

FGM was first introduced by National Aerospace Laboratory of Japan in 1984 to create thermal barrier for a space shuttle which could withstand high temperature gradient of $1000 \mathrm{~K}$ across a $10 \mathrm{~mm}$ thick section. Zhang et al. (1993) modeled an isotropic ceramic/metal laminated beam subjected to an abrupt heating condition and demonstrated the influence of thermomechanical coupling for thermal shock response. Reddy (2000) presented theoretical formulations and solutions for rectangular plates based on Navier's solution technique using steady state heat conduction equation for static, dynamic and transient responses including von-Karman type geometric nonlinearity. Also, he stated that the material gradation plays a crucial role in the analysis of FGM plates. Reddy and Cheng (2001) adopted asymptotic solution method to study the thermomechanical behaviour of simply supported FGM plates. Shen (2002) gave a nonlinear bending analysis of simply supported shear deformable FGM plates subjected to a transverse uniform or sinusoidal load in thermal environments based on Reddy's higher order shear deformation theory with temperature dependent material properties. Yang and Shen (2003) extended the work to study the large deflection of thin FGM plates. Tsukamoto (2003) investigated transient thermal-stress in a ceramicmetal FGM plate combining Eshelby's equivalent (Eshelby, 1957) and Mori-Tanaka method (Mori and Tanaka, 1973) based on Classical Plate Laminate theory. Brischetto et al. (2008) adopted Unified Formulation by Carrera (2000) to study the behavior of a simply supported rectangular plate subjected to thermo-mechanical loadings using Mori-Tanaka material variation through the thickness. Zenkour (2006) presented benchmark three dimensional elasticity solutions for an FGM plate subjected to normal pressure for exponentially graded plates. Matsunaga (2009) studied thermo-mechanical deformations of simply supported rectangular plates for uniform rise in temperature using power-law variation of material properties based on various 2-D plate theories. Most of the theories used for the analysis of FGM plates are extensions of composite laminates.

In the present paper a simply supported FGM plate subjected to thermal loads is studied based on higher order shear deformation theory with twelve degrees of freedom (HSDT-12). Material properties are assumed to vary according to Power-Law function, while temperature variation follows steady state heat conduction equation through the thickness. Extensive numerical results are presented for various parametric variations like length to 
thickness ratio, length to breadth ratio, and power law coefficient to study the response of FGM plate.

\section{THEORITICAL FORMULATIONS}

A simply supported functionally graded rectangular/square plate of length $\mathrm{a}$, breadth $\mathrm{b}$ and uniform thickness $\mathrm{h}$ along $\mathrm{x}-$ , y- and z- directions respectively subjected to a thermal load of intensity $\mathrm{T}_{0}$ at bottom (metal) and $\mathrm{T}_{1}$ at the top (ceramic) surface is as shown in figure.1. Through the thickness variation of material properties and temperature and their theoretical formulations and solutions are discussed in the next sections.

\subsection{Material properties}

FG plate is assumed to be transversely isotropic and hence the poison's ratio $v$ is kept constant. Material properties are assumed to be graded in the thickness direction and obey Power-Law function as in eqn. (1).

$\mathrm{E}_{\mathrm{z}}=\mathrm{E}_{\mathrm{m}}+\left(\mathrm{E}_{\mathrm{c}}-\mathrm{E}_{\mathrm{m}}\right) \mathrm{V}_{\mathrm{f}}^{\mathrm{p}}$

$\alpha_{\mathrm{z}}=\alpha_{\mathrm{m}}+\left(\alpha_{\mathrm{c}}-\alpha_{\mathrm{m}}\right) \mathrm{V}_{\mathrm{f}}^{\mathrm{p}}$

$\mathrm{u}(\mathrm{x}, \mathrm{y}, \mathrm{z})=\mathrm{u}_{0}(\mathrm{x}, \mathrm{y})+\mathrm{z} \theta_{\mathrm{x}}(\mathrm{x}, \mathrm{y})+\mathrm{z}^{2} \mathrm{u}_{0}^{*}(\mathrm{x}, \mathrm{y})+\mathrm{z}^{3} \theta_{\mathrm{x}}^{*}(\mathrm{x}, \mathrm{y})$

$\mathrm{v}(\mathrm{x}, \mathrm{y}, \mathrm{z})=\mathrm{v}_{0}(\mathrm{x}, \mathrm{y})+\mathrm{z} \theta_{\mathrm{y}}(\mathrm{x}, \mathrm{y})+\mathrm{z}^{2} \mathrm{v}_{0}^{*}(\mathrm{x}, \mathrm{y})+\mathrm{z}^{3} \theta_{\mathrm{y}}^{*}(\mathrm{x}, \mathrm{y})$

$w(x, y, z)=w_{0}(x, y)+z \theta_{z}(x, y)+z^{2} w_{0}^{*}(x, y)+z^{3} \theta_{z}^{*}(x, y)$

where, $\mathrm{u}_{0}, \mathrm{v}_{0}$ represents in-plane displacements and $\mathrm{w}_{0}$ is the transverse displacement at any point (x,y) in the middle-plane of the plate. $\theta_{\mathrm{x}}$ and $\theta_{\mathrm{y}}$ are the rotations of the normal to the middle plane about $\mathrm{y}$ - and $\mathrm{x}$-axes respectively. The terms $\mathrm{u}_{0}^{*}, \mathrm{v}_{0}^{*}, \mathrm{w}_{0}^{*}$, $\theta_{\mathrm{x}}^{*}, \theta_{\mathrm{y}}^{*}, \theta_{\mathrm{z}}^{*}$ and $\theta_{\mathrm{z}}$ are the higher-order terms in Taylor's series expansion which represents transverse cross sectional deformation modes. The stress-strain relationship for an FGM plate which includes the effect of transverse shear deformation is given by eqn. (3). The stresses and strains with respect to plate axes are denoted by $\left(\sigma_{\mathrm{x}}, \sigma_{\mathrm{y}}, \sigma_{\mathrm{z}}, \tau_{\mathrm{xy}}, \tau_{\mathrm{xz}}, \tau_{\mathrm{yz}}\right)$ and $\left(\varepsilon_{\mathrm{x}}, \varepsilon_{\mathrm{y}}, \varepsilon_{\mathrm{z}}, \tau_{\mathrm{xy}}, \tau_{\mathrm{yz}}\right.$, $\tau_{\mathrm{xz}}$ ) respectively. The elements of stiffness matrix $\mathrm{Q}$ are given by eqn. (4).

$\left\{\begin{array}{c}\sigma_{\mathrm{x}} \\ \sigma_{\mathrm{y}} \\ \sigma_{\mathrm{z}} \\ \tau_{\mathrm{xy}} \\ \tau_{\mathrm{yz}} \\ \tau_{\mathrm{xz}}\end{array}\right\}=\left[\begin{array}{cccccc}\mathrm{Q}_{11} & \mathrm{Q}_{12} & \mathrm{Q}_{13} & 0 & 0 & 0 \\ \mathrm{Q}_{12} & \mathrm{Q}_{22} & \mathrm{Q}_{23} & 0 & 0 & 0 \\ \mathrm{Q}_{13} & \mathrm{Q}_{23} & \mathrm{Q}_{33} & 0 & 0 & 0 \\ 0 & 0 & 0 & \mathrm{Q}_{44} & 0 & 0 \\ 0 & 0 & 0 & 0 & \mathrm{Q}_{55} & 0 \\ 0 & 0 & 0 & 0 & 0 & \mathrm{Q}_{66}\end{array}\right]\left\{\begin{array}{c}\varepsilon_{\mathrm{x}}-\alpha_{\mathrm{z}} \Delta \mathrm{T} \\ \varepsilon_{\mathrm{y}}-\alpha_{\mathrm{z}} \Delta \mathrm{T} \\ \varepsilon_{\mathrm{z}}-\alpha_{\mathrm{z}} \Delta \mathrm{T} \\ \gamma_{\mathrm{xy}} \\ \gamma_{\mathrm{yz}} \\ \gamma_{\mathrm{xz}}\end{array}\right\}$

$\mathrm{Q}_{11}=\mathrm{Q}_{22}=\mathrm{Q}_{33}=\frac{\mathrm{E}_{\mathrm{z}}\left(1-\mathrm{v}^{2}\right)}{\eta} ; \quad \mathrm{Q}_{44}=\mathrm{Q}_{55}=\mathrm{Q}_{66}=\frac{\mathrm{E}_{\mathrm{z}}}{\left(1-\mathrm{v}^{2}\right)}$;

$\mathrm{Q}_{13}=\mathrm{Q}_{23}=\mathrm{Q}_{12}=\mathrm{Q}_{21}=\mathrm{Q}_{31}=\mathrm{Q}_{32}=\frac{\mathrm{E}_{\mathrm{z}}\left(v+v^{2}\right)}{\eta} ; \quad \eta=\left(1-3 v^{2}-2 v^{3}\right)$ 


\subsection{Thermal analysis}

The variation of temperature across the plate thickness is assumed to be nonlinear and is solved based on one dimensional (1-D) steady state heat conduction equation with the relevant boundary conditions at top and bottom surface of the plate as given in eqn. (5).

$-\frac{\mathrm{d}}{\mathrm{dz}}\left(\mathrm{k}_{\mathrm{z}} \frac{\mathrm{dT}}{\mathrm{dz}}\right)=0 ; \quad \mathrm{T}\left(\mathrm{z}=\frac{\mathrm{h}}{2}\right)=\mathrm{T}_{1} \quad$ and $\quad \mathrm{T}\left(\mathrm{z}=-\frac{\mathrm{h}}{2}\right)=\mathrm{T}_{0}$

Hence, the Taylor series solution for the temperature distribution through the thickness is evaluated using eqn. (6).

$$
\Delta \mathrm{T}=\mathrm{T}_{0}+\left(\mathrm{T}_{1}-\mathrm{T}_{0}\right) \frac{\sum_{\mathrm{n}=0}^{9} \frac{(-1)^{\mathrm{n}}\left(\frac{\left(\mathrm{k}_{\mathrm{c}}-\mathrm{k}_{\mathrm{m}}\right)}{\mathrm{k}_{\mathrm{m}}}\right)^{\mathrm{n}}}{(\mathrm{np}+1)} \mathrm{V}_{\mathrm{f}}^{(\mathrm{np}+1)}}{\sum_{\mathrm{n}=0}^{9} \frac{(-1)\left(\frac{\left(\mathrm{k}_{\mathrm{c}}-\mathrm{k}_{\mathrm{m}}\right)}{\mathrm{k}_{\mathrm{m}}}\right)^{\mathrm{n}}}{(\mathrm{np}+1)}} ;
$$

\subsection{Equations of equilibrium and boundary conditions}

Principle of Minimum Potential Energy (PMPE) is used to derive the equations of equilibrium for stress analysis of FGM plates and the associated equations for the present model are listed below:
(1) $\delta \mathrm{u}_{0}:\left(\frac{\partial \mathrm{N}_{\mathrm{x}}}{\partial \mathrm{x}}+\frac{\partial \mathrm{N}_{\mathrm{xy}}}{\partial \mathrm{y}}\right)=0$
(2) $\delta \mathrm{v}_{0}:\left(\frac{\partial \mathrm{N}_{\mathrm{y}}}{\partial \mathrm{y}}+\frac{\partial \mathrm{N}_{\mathrm{xy}}}{\partial \mathrm{x}}\right)=0$
(3) $\delta \mathrm{w}_{0}:\left(\frac{\partial \mathrm{Q}_{\mathrm{x}}}{\partial \mathrm{x}}+\frac{\partial \mathrm{Q}_{\mathrm{y}}}{\partial \mathrm{y}}+\mathrm{p}_{\mathrm{z}}^{+}\right)=0$
(4) $\delta \theta_{\mathrm{x}}:\left(\frac{\partial \mathbf{M}_{\mathrm{x}}}{\partial \mathrm{x}}+\frac{\partial \mathbf{M}_{\mathrm{xy}}}{\partial \mathrm{y}}-\mathrm{Q}_{\mathrm{x}}\right)=0$
(5) $\delta \theta_{\mathrm{y}}:\left(\frac{\partial \mathrm{M}_{\mathrm{y}}}{\partial \mathrm{y}}+\frac{\partial \mathrm{M}_{\mathrm{xy}}}{\partial \mathrm{x}}-\mathrm{Q}_{\mathrm{y}}\right)=0$
(6) $\delta \theta_{\mathrm{z}}:\left(\frac{\partial \mathrm{S}_{\mathrm{x}}}{\partial \mathrm{x}}+\frac{\partial \mathrm{S}_{\mathrm{y}}}{\partial \mathrm{y}}-\mathrm{N}_{\mathrm{z}}+\frac{\mathrm{h}}{2} \mathrm{p}_{\mathrm{z}}^{+}\right)=0$
(7) $\delta \mathrm{u}_{0}^{*}:\left(\frac{\partial \mathrm{N}_{\mathrm{x}}^{*}}{\partial \mathrm{x}}+\frac{\partial \mathrm{N}_{\mathrm{xy}}^{*}}{\partial \mathrm{y}}-2 \mathrm{~S}_{\mathrm{x}}\right)=0$
$(8) \delta \mathrm{v}_{0}^{*}:\left(\frac{\partial \mathrm{N}_{\mathrm{y}}^{*}}{\partial \mathrm{y}}+\frac{\partial \mathrm{N}_{\mathrm{xy}}^{*}}{\partial \mathrm{x}}-2 \mathrm{~S}_{\mathrm{y}}\right)=0$
(9) $\delta \mathrm{w}_{0}^{*}:\left(\frac{\partial \mathrm{Q}_{\mathrm{x}}^{*}}{\partial \mathrm{x}}+\frac{\partial \mathrm{Q}_{\mathrm{y}}^{*}}{\partial \mathrm{y}}-2 \mathrm{M}_{\mathrm{z}}^{*}+\frac{\mathrm{h}^{2}}{4} \mathrm{p}_{\mathrm{z}}^{+}\right)=0$
(10) $\delta \theta_{\mathrm{x}}^{*}:\left(\frac{\partial \mathrm{M}_{\mathrm{x}}^{*}}{\partial \mathrm{x}}+\frac{\partial \mathrm{M}_{\mathrm{xy}}^{*}}{\partial \mathrm{y}}-3 \mathrm{Q}_{\mathrm{x}}^{*}\right)=0$
(11) $\delta \theta_{\mathrm{y}}^{*}:\left(\frac{\partial \mathrm{M}_{\mathrm{y}}^{*}}{\partial \mathrm{y}}+\frac{\partial \mathrm{M}_{\mathrm{xy}}^{*}}{\partial \mathrm{x}}-3 \mathrm{Q}_{\mathrm{y}}^{*}\right)=0$
(12) $\delta \theta_{\mathrm{z}}^{*}:\left(\frac{\partial \mathrm{S}_{\mathrm{x}}^{*}}{\partial \mathrm{x}}+\frac{\partial \mathrm{S}_{\mathrm{y}}^{*}}{\partial \mathrm{y}}-3 \mathrm{~N}_{\mathrm{z}}^{*}+\frac{\mathrm{h}^{3}}{8} \mathrm{p}_{\mathrm{z}}^{+}\right)=0$

And the stress resultants are defined as,

$$
\begin{aligned}
& {\left[\begin{array}{cccc}
\mathrm{N}_{\mathrm{x}} & \mathrm{N}_{\mathrm{x}}^{*} & \mathrm{M}_{\mathrm{x}} & \mathrm{M}_{\mathrm{x}}^{*} \\
\mathrm{~N}_{\mathrm{y}} & \mathrm{N}_{\mathrm{y}}^{*} & \mathrm{M}_{\mathrm{y}} & \mathrm{M}_{\mathrm{y}}^{*} \\
\mathrm{~N}_{\mathrm{z}} & \mathrm{N}_{\mathrm{z}}^{*} & \mathrm{M}_{\mathrm{z}}^{*} & 0 \\
\mathrm{~N}_{\mathrm{xy}} & \mathrm{N}_{\mathrm{xy}}^{*} & \mathrm{M}_{\mathrm{xy}} & \mathrm{M}_{\mathrm{xy}}^{*}
\end{array}\right]=\int_{-\mathrm{h} / 2}^{+\mathrm{h} / 2}\left\{\begin{array}{c}
\sigma_{\mathrm{x}} \\
\sigma_{\mathrm{y}} \\
\sigma_{\mathrm{z}} \\
\tau_{\mathrm{xy}}
\end{array}\right\}\left(1, \mathrm{z}^{2}, \mathrm{z}, \mathrm{z}^{3}\right) \mathrm{dz}} \\
& {\left[\begin{array}{llll}
\mathrm{Q}_{\mathrm{x}} & \mathrm{Q}_{\mathrm{x}}^{*} & \mathrm{~S}_{\mathrm{x}} & \mathrm{S}_{\mathrm{x}}^{*} \\
\mathrm{Q}_{\mathrm{y}} & \mathrm{Q}_{\mathrm{y}}^{*} & \mathrm{~S}_{\mathrm{y}} & \mathrm{S}_{\mathrm{y}}^{*}
\end{array}\right]=\int_{-\mathrm{h} / 2}^{+\mathrm{h} / 2}\left\{\begin{array}{c}
\tau_{\mathrm{xz}} \\
\tau_{\mathrm{yz}}
\end{array}\right\}\left(1, \mathrm{z}^{2}, \mathrm{z}, \mathrm{z}^{3}\right) \mathrm{dz}}
\end{aligned}
$$

The closed form solutions are obtained using Navier's solution technique for a simply supported boundary condition. In plane stresses are computed by substituting the strains in the constitutive relations, while the transverse stresses are obtained by integrating the 3-D elasticity equations of equilibrium. 


\section{RESULTS AND DISCUSSIONS}

In this section, the accuracy of the model is established by comparing the displacements and stresses with the 3-D elasticity solutions of Reddy and Cheng (2001) for an FGM plate subjected to mechanical loading. Later, parametric studies are carried out for an FGM plate subjected to steady state thermal loads. For all the problems, a rectangular FGM plate with simply supported edges, viz. SS-1 boundary conditions with in-plane sinusoidal variation of loads is considered for the analysis. Numerical results presented in the tables are obtained using Navier's solution technique for a Monel-Zirconia FGM plate with the following material properties.

$\begin{array}{lll}\text { Metal (Monel): } & \mathrm{E}_{\mathrm{m}}=227.24 \mathrm{Gpa}, & \alpha_{\mathrm{m}}=15^{*} 10^{-6} \mathrm{~K}^{-1}, \\ \mathrm{k}_{\mathrm{m}}=25 \mathrm{WmK}^{-1} & & \\ \text { Ceramic (Zirconia): } & \mathrm{E}_{\mathrm{c}}=125.83 \mathrm{Gpa}, & \alpha_{\mathrm{c}}=10^{*} 10^{-6} \mathrm{~K}^{-1}, \\ \mathrm{k}_{\mathrm{m}}=2.09 \mathrm{WmK}^{-1} & & \end{array}$

The results reported are non-dimensionalized using the following form

$$
\begin{aligned}
& (\bar{u}, \bar{v}, \bar{w})=\frac{(u, v, w)}{P a} \\
& \left(\bar{\sigma}_{x}, \bar{\sigma}_{y}, \bar{\sigma}_{z}, \bar{\tau}_{x y}, \bar{\tau}_{x z}, \bar{\tau}_{y z},\right)=\frac{\left(\sigma_{x}, \sigma_{y}, \sigma_{z}, \tau_{x y}, \tau_{x z}, \tau_{y z}\right)}{P E^{*}}
\end{aligned}
$$

Where, $\mathrm{P}$ can be evaluated either by $\mathrm{P}=\frac{\mathrm{p}_{0}}{\mathrm{E}^{*}}$ for applied transverse mechanical load or $\mathrm{P}=\alpha^{*} \mathrm{~T}_{1}$ for applied thermal load $\mathrm{T}_{1}$ at the ceramic surface. The scale factors considered are $\mathrm{E}^{*}=1 \mathrm{GPa}$ and $\alpha^{*}=10^{-6} \mathrm{~K}^{-1}$.

The displacements and stresses presented in the tables are at specified location (i.e. $\mathrm{x}-, \mathrm{y}-$ and $\mathrm{z}$ - coordinates) as given below

In-plane displacement $(\overline{\mathrm{u}}):(0, \mathrm{~b} / 2, \mathrm{~h} / 2)$

Transverse displacement $(\overline{\mathrm{W}}):(\mathrm{a} / 2, \mathrm{~b} / 2, \mathrm{~h} / 2)$

In-plane normal stress $\left(\bar{\sigma}_{\mathrm{x}}\right):(\mathrm{a} / 2, \mathrm{~b} / 2,0)$

Transverse normal stress $\left(\bar{\sigma}_{\mathrm{Z}}\right):(\mathrm{a} / 2, \mathrm{~b} / 2,0)$

In-plane shear stress $\left(\bar{\tau}_{\mathrm{xy}}\right):(0,0,0)$

Transverse shear stress $\left(\bar{\tau}_{\mathrm{xz}}\right):(0, \mathrm{~b} / 2,0)$

\section{Example 1:}

A simply supported square FGM plate subjected to a sinusoidally distributed transverse normal pressure of intensity $\mathrm{p}_{0}$ is studied. The numerical results are compared with the 3-D exact solutions reported by Reddy and Cheng, (2001) to assess the accuracy of the present model. The nondimensionalized displacements and stresses for various side to thickness $(\mathrm{a} / \mathrm{b})$ ratio with power law parameter, $\mathrm{p}=2$ and $\mathrm{m}=\mathrm{n}=1$, are given in Table-1. It is observed that the percentage error is less than $3 \%$ for all $\mathrm{a} / \mathrm{h}$ ratios. The results predicted by HSDT-12 model are in good agreement with the 3-D elasticity solutions in case of FGM plates subjected to mechanical loading; henceforth the same model is extended to study the thermal stresses in FGM plates.

\section{Example 2:}

In this example, an FGM plate subjected to nonlinear thermal loads is studied. The non-dimensionalized displacements and stresses presented in Table 2 are obtained by considering nonlinear temperature profile across the thickness obtained by solving one dimensional steady -state heat conduction equation. Numerical results are presented for various power law parameters (p), length to thickness $(\mathrm{a} / \mathrm{h})$ ratio and length to breadth $(\mathrm{a} / \mathrm{b})$ ratio. From the results it is found that the in-plane normal stress $\left(\bar{\sigma}_{\mathrm{x}}\right)$ increases with increase in parametric values, whereas the in-plane shear stress $\left(\bar{\tau}_{\mathrm{xy}}\right)$, transverse shear stress $\left(\bar{\tau}_{\mathrm{xz}}\right)$ and transverse normal stresses $\left(\bar{\sigma}_{z}\right)$ decreases with increase in parametric values.

\section{CONCLUSIONS}

Analytical formulations and solutions hitherto not reported in the literature for thermal analysis of FGM plates are presented based on higher order shear deformation theory with twelve degrees of freedom which includes the effect of transverse shear and transverse normal stress/strain. Through the thickness variation of material properties obey power law function and thermal load according to one dimensional steady state heat conduction equation. Parametric studies are performed and numerical results are presented for in-plane and transverse stresses. Based on the investigation carried out it has been concluded that the higher order refined computational model with twelve degrees of freedom (HSDT12) could predict the complete behavior of FGM plates as accurately as the 3-D exact elasticity method for all the parametric variations considered.

\section{REFERENCES}

1. Brischetto, S., Leetsch, R., Carrera, E., Wallmerspergerb, T. and Kroplin, B., "ThermoMechanical Bending of Functionally Graded Plates", J Therm Stresses, V. 31, No. 3, Feb. 2008, pp. 286-308

2. Carrera, E., "An Assessment of Mixed and Classical Theories for the Thermal Stress Analysis of Orthotropic Multilayered Plates", J Therm Stresses, V. 23, Jan. 2000, 797-831

3. Eselby, J. D., "The Determination of the Elastic Field of an Ellipsoidal Inclusion, and Related Problems", Proc R Soc Lond Ser, V. 241, No. 1226, Aug. 1957, 376-96.

4. Kant, T., "Numerical Analysis of Thick Plates", Comput Method Appl M., V. 31, July. 1982, pp. 1-18

5. Matsunaga, H., "Stress Analysis of Functionally Graded Plates Subjected to Thermal and Mechanical Loadings", Compos Struct, V. 87, No.4, Feb. 2009, 344-357

6. Mori, T and Tanaka, K. "Average Stress in Matrix and Average Elastic Energy of Materials with Misfitting Inclusions”, Acta Metall, V. 21, May 1973, 571-4. 
7. Reddy, J. N., “Analysis of Functionally Graded Plates”, Int J Numer Meth Eng, V. 47, Jan. 2000, pp. 663-684

8. Reddy, J. N. and Cheng, Z. Q., "Three-Dimensional Thermomechanical Deformations of Functionally Graded Rectangular Plates", Eur J Mech A-Solid, V. 20, No. 5, July. 2001, pp. 841-855

9. Shen, H. S., "Nonlinear Bending Response of Functionally Graded Plates Subjected to Transverse Loads and in Thermal Environments", Int J Mech Sci., V. 44, No. 3, Mar. 2002, pp. 561-584

10. Tsukamoto, H., "Analytical Method of Inelastic Thermal Stresses in a Functionally Graded Material Plate by a Combination of Micro- and Macro Mechanical Approaches", Compos Part B-Eng., V. 34, No. 6, Sep. 2003, pp. 561-568.
11. Yang, J., and Shen, H. S., "Nonlinear Analysis of Functionally Graded Plates under Transverse and InPlane Loads", Int J Nonlinear Mech., V. 38, No. 4, Jun. 2003, pp. 467-482

12. Zenkour, A.M., "Benchmark Trigonometric and 3-D Elasticity Solutions for an Exponentially Graded Thick Rectangular Plate." Arch Appl Mech., V. 77, No. 4, Apr. 2007, 197-214

13. Zhang, Q. J., Zhang, L. M. and Yuan, R. Z., “A Coupled Thermoelasticity Model of Functionally Gradient Materials under Sudden High Surface Heating", Ceram. Trans. Functionally Gradient Materials, V. 34, 1993, 99-106.

Table 1: Displacements and stresses in an FGM plate subjected to sinusoidal transverse load.

\begin{tabular}{|c|c|c|c|c|}
\hline \multirow{2}{*}{\multicolumn{2}{|c|}{$\mathrm{a} / \mathrm{b}=1, \mathrm{p}=2, \mathrm{~m}=\mathrm{n}=1$}} & \multicolumn{3}{|c|}{$\mathbf{a} / \mathbf{h}$} \\
\hline & & \multirow{2}{*}{$\begin{array}{c}\mathbf{4} \\
0.004021 \\
\end{array}$} & \multirow{2}{*}{$\begin{array}{c}\mathbf{1 0} \\
0.02617 \\
\end{array}$} & \multirow{2}{*}{$\begin{array}{c}\mathbf{5 0} \\
0.6603 \\
\end{array}$} \\
\hline \multirow{2}{*}{$\overline{\mathrm{u}}$} & $3 \mathrm{D}-$ Exact $^{\$}$ & & & \\
\hline & HSDT-12 & $0.00402[-0.02]^{\mathrm{p}}$ & $0.026172[0.01]$ & $0.6603[0.00]$ \\
\hline \multirow{2}{*}{$\overline{\mathrm{w}}$} & $3 \mathrm{D}-\mathrm{Exact}^{\$}$ & -0.0135 & -0.1689 & -20.3200 \\
\hline & HSDT-12 & $-0.0135[-0.01]$ & $-0.1689[-0.01]$ & $-20.3145[-0.03]$ \\
\hline \multirow{2}{*}{$\bar{\sigma}_{x}$} & $3 \mathrm{D}-$ Exact $^{\$}$ & -0.2037 & -0.8722 & -19.5600 \\
\hline & HSDT-12 & $-0.1976[-2.98]$ & $-0.8836[1.31]$ & $-20.0571[2.54]$ \\
\hline \multirow{2}{*}{$\bar{\tau}_{\mathrm{xz}}$} & $3 \mathrm{D}-\mathrm{Exact}^{\$}$ & -0.9500 & -2.3960 & -12.0000 \\
\hline & HSDT-12 & $-0.9458[-0.44]$ & $-2.3994[0.14]$ & $-12.0290[0.24]$ \\
\hline \multirow{2}{*}{$\bar{\sigma}_{z}$} & $3 \mathrm{D}-$ Exact $^{\$}$ & -0.5130 & -0.5142 & -0.5141 \\
\hline & HSDT-12 & $-0.5136[0.12]$ & $-0.5142[0.00]$ & $-0.5140[-0.02]$ \\
\hline
\end{tabular}

${ }^{\mathrm{T}}$ Numbers in parentheses are the percentage error with respect to 3-D elasticity values

${ }^{\$}$ Reddy, J., and Cheng, Z. Q. (2001).

Table 2: In-plane and transverse stresses in an FGM plate subjected to thermal loads.

\begin{tabular}{|c|c|c|c|c|c|c|c|c|c|c|c|c|c|}
\hline \multirow{2}{*}{$\mathbf{a} / \mathbf{b}$} & \multirow{2}{*}{$\mid \begin{array}{l}\mathbf{a} / \mathbf{h} \\
\mathbf{p}\end{array}$} & $\longrightarrow$ & \multicolumn{2}{|c|}{$\overline{\boldsymbol{\sigma}}_{\mathrm{x}}$} & \multicolumn{3}{|c|}{$\bar{\tau}_{x y}$} & \multicolumn{3}{|c|}{$\bar{\tau}_{\mathrm{xz}}$} & \multicolumn{3}{|c|}{$\bar{\sigma}_{\mathrm{z}}$} \\
\hline & & 4 & 20 & 100 & 4 & 20 & 100 & 4 & 20 & 100 & 4 & 20 & 100 \\
\hline \multirow{4}{*}{1} & 1 & -258.85 & -228.61 & -227.37 & -316.26 & -333.43 & -334.16 & 5.7194 & 1.2935 & 0.2599 & 5.4214 & 0.3351 & 0.0136 \\
\hline & 2 & -414.74 & -378.75 & -377.27 & -396.99 & -416.33 & -417.16 & 6.1228 & 1.3740 & 0.2760 & 1.0715 & 0.1783 & 0.0074 \\
\hline & 5 & -680.23 & -633.14 & -631.19 & -550.27 & -573.74 & -574.75 & -4.0358 & -0.6613 & -0.1310 & -8.0552 & -0.1500 & -0.0057 \\
\hline & 10 & -780.91 & -724.81 & -722.49 & -649.17 & -676.70 & -677.88 & -12.3244 & -2.2947 & -0.4575 & -12.0847 & -0.2772 & -0.0107 \\
\hline \multirow{4}{*}{1.5} & 1 & -395.45 & -357.48 & -355.92 & -282.62 & -307.35 & -308.44 & 5.2605 & 1.2894 & 0.2599 & 5.8853 & 0.5394 & 0.0221 \\
\hline & 2 & -585.38 & -539.64 & -537.75 & -356.07 & -383.81 & -385.05 & 5.6624 & 1.3700 & 0.2760 & -1.5849 & 0.2838 & 0.0120 \\
\hline & 5 & -915.70 & -854.82 & -852.29 & -495.51 & -529.00 & -530.51 & -4.4829 & -0.6652 & -0.1311 & -17.2890 & -0.2513 & -0.0093 \\
\hline & 10 & -1059.11 & -986.29 & -983.27 & -584.68 & -623.94 & -625.71 & -12.8461 & -2.2993 & -0.4576 & -24.6671 & -0.4596 & -0.0175 \\
\hline \multirow{2}{*}{2} & 1 & -478.93 & -429.92 & -427.92 & -234.76 & -265.84 & -267.29 & 4.6482 & 1.2838 & 0.2599 & 3.1782 & 0.8186 & 0.0340 \\
\hline & 2 & -689.63 & -630.09 & -627.63 & -297.37 & -332.04 & -333.68 & 5.0455 & 1.3644 & 0.2760 & -9.0778 & 0.4238 & 0.0184 \\
\hline
\end{tabular}




\begin{tabular}{|c|c|c|c|c|c|c|c|c|c|c|c|c|c|}
\hline & 5 & -1059.73 & -979.47 & -976.12 & -416.19 & -457.74 & -459.75 & -5.0791 & -0.6707 & -0.1311 & -34.9255 & -0.4030 & -0.0143 \\
\hline & 10 & -1229.67 & -1133.33 & -1129.32 & -491.22 & -539.89 & -542.25 & -13.5409 & -2.3057 & -0.4576 & -47.9243 & -0.7267 & -0.0269 \\
\hline \multirow{4}{*}{2.5} & 1 & -535.34 & -472.01 & -469.43 & -192.68 & -228.59 & -230.40 & 3.9029 & 1.2765 & 0.2598 & -5.2989 & 1.1663 & 0.0492 \\
\hline & 2 & -759.95 & -682.65 & -679.45 & -245.82 & -285.58 & -287.63 & 4.2901 & 1.3571 & 0.2759 & -24.2631 & 0.5907 & 0.0266 \\
\hline & 5 & -1156.92 & -1051.92 & -1047.52 & -346.62 & -393.80 & -396.30 & -5.8058 & -0.6778 & -0.1312 & -64.4344 & -0.6148 & -0.0208 \\
\hline & 10 & -1345.19 & -1218.81 & -1213.53 & -409.30 & -464.48 & -467.42 & -14.3837 & -2.3140 & -0.4577 & -86.0074 & -1.0901 & -0.0391 \\
\hline
\end{tabular}

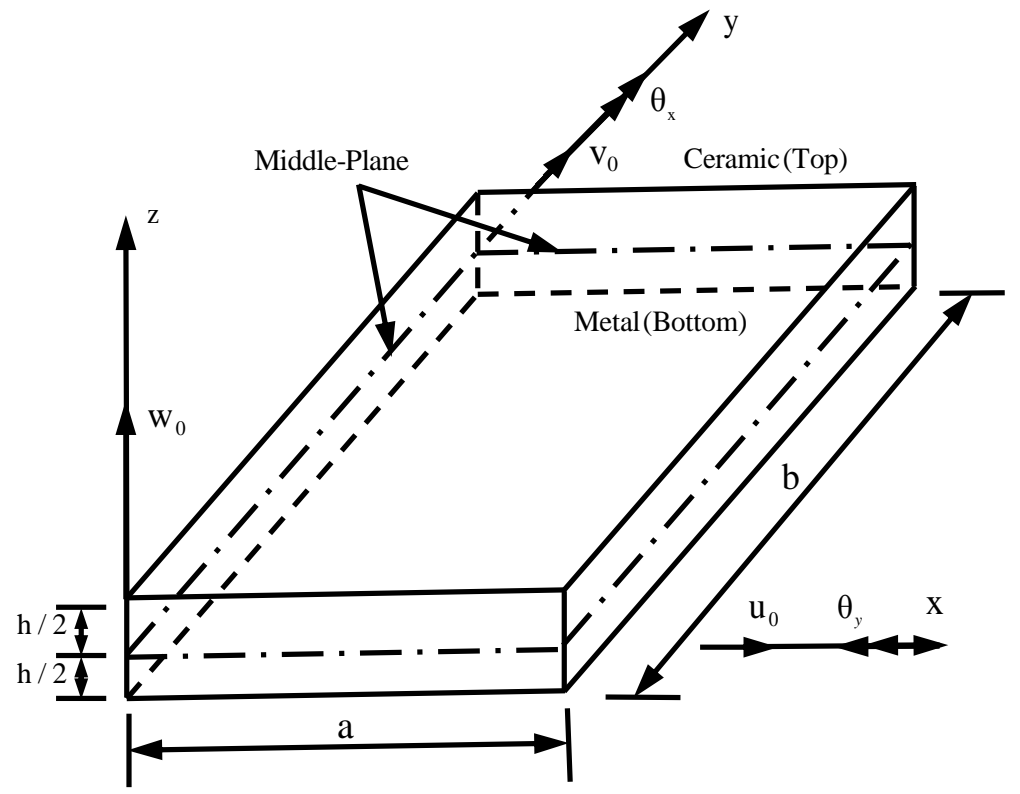

(x, y, z) - Plate Reference Axes

Figure.1. FGM plate geometry with positive set of reference axes and displacement components 